Volume 4, Issue 1 Janaury-March 2019, Pages: 275, DOI: http://dx.doi.org/10.19082/ah275

\title{
SYNTHESIS OF NEW MODIFIEDS CYCLODEXTRINS AS PHARMACEUTICALS VECTORES
}

\author{
Assia Keniche ${ }^{1,2}$, Malti Ibtissem², Si Said Mohammed El Amine ${ }^{3}$, Joseph Kajima Mulengi ${ }^{3}$ \\ keniche_assia@yahoo.fr
}

1: PhD of Bioorganic and Therapeutic Chemistry, Maghnia Center University, Tlemcen, Algeria

2: Laboratory of Organic Chemistry, Natural Products and Analysis University of Tlemcen, Algeria

3: Faculté des Sciences, University of Tlemcen, Algeria

\section{TYPE OF ARTICLE: CONFERENCE ABSTRACT}

\begin{abstract}
Objective: The aim of this study was to synthesize new modified Cyclodextrins (CDs), for study of inclusion complex of drug with CD to improve water solubility.

Methods: In this study, the formulation of bioactive molecules (Baclofen ${ }^{\circledR}$, aziridine synthesis and active propolis) with amphiphilic cyclodextrin ( $\beta$-CD-amph) was prepared from native $\beta$-cyclodextrin $(\beta-C D)$ via the simple co-precipitation method at the University of Tlemcen, Algeria (2016).

Results: It was of interest to find a model of molecule derivatives that would be sufficiently water-stable and form a stable complex with ( $\beta$-CD-amph) in aqueous medium, so that it could be used as a reference in future formulations or vectorization work. Among the nanoformulation, NMR studies of the inclusion complex of this derivative with b-cyclodextrin provided useful parameters related to the stoichiometry of the complex and the association with stant Ka.

Conclusion: The geometry of the complex was assessed by 2D-ROESY experiments, suggesting a deep insertion of the guest into the cavity of ( $\beta$-CD-amph).

KEYWORDS: Cyclodextrin, Bioactive molecules, Baclofene ${ }^{\circledR}$
\end{abstract}

\footnotetext{
Abstracts of Third International Conference on Health Sciences and Medical Technologies, October 2018, Tlemcen, Algeria (ICHSMT-18)

(C) 2019 The Authors. This is an open access article under the terms of the Creative Commons Attribution-NonCommercialNoDerivs License, which permits use and distribution in any medium, provided the original work is properly cited, the use is non-commercial and no modifications or adaptations are made.
} 